\title{
La cerámica aguada en las tierras altas (Puna Meridional Argentina, Catamarca)
}

\section{Aguada pottery in the highlands (Puna Meridional Argentina, Catamarca)}

\author{
Martín Tomás Casanova Menéndez ${ }^{1,2}$ https://orcid.org/0000-0003-3428-7698 \\ Daniel Enzo Olivera ${ }^{2,3}$ https://orcid.org/0000-0003-0582-241X \\ Martina Inés Pérez ${ }^{2,3}$ https://orcid.org/0000-0002-5340-934X \\ ${ }^{1}$ CONICET, ARGENTINA \\ ${ }^{2}$ Instituto Nacional de Antropología y Pensamiento Latinoamericano, 3 de febrero 1370 (1426), \\ Capital Federal, ARGENTINA. Email: martincas89@hotmail.com. \\ ${ }^{3}$ Universidad de Buenos Aires y CONICET, ARGENTINA. E-mail: deolivera@gmail.com y \\ martinainesperez@hotmail.com
}

\section{Resumen \\ En este trabajo se presenta un estudio tecnológico y decorativo de una muestra cerámica identificada con la tipología Aguada proveniente del sitio Casa Chávez Montículos en Antofagasta de la Sierra (Puna Meridional Argentina). Las características de esta cerámica, resultado del análisis propuesto, serán comparadas con similares atributos de las piezas provenientes de los valles mesotermales de Hualfín y Abaucán analizadas por otros autores. El objetivo de la comparación se dirige a identificar similitudes y diferencias en los distintos pasos del proceso de producción relacionado con este tipo de alfarería. De esta forma, se contribuirá con nuevos datos a la discusión, ya planteada (Olivera, 1992, 1997), respecto de la región de la que provino la influencia que llevó a la presencia Aguada en Antofagasta de la Sierra durante el Período Formativo Medio y Tardío (2000 a 1100 ańos AP), y con un análisis orientado a observar las características particulares de dicho fenómeno en la microrregión.}

Palabras claves: cerámica Aguada, tecnología, estilo, puna, Período Formativo.

\begin{abstract}
This paper presents a technological and decorative study of a ceramic sample identified with the Aguada typology from the Casa Chávez Montículos site in Antofagasta de la Sierra, (Puna Meridional Argentina). The characteristics of this pottery, result of the proposed analysis, will be compared with similar attributes of the pieces coming from the mesothermal valleys of Hualfín and Abaucán analyzed by other authors. The objective of the comparison is to identify similarities and differences in the different steps of the production process of this type of pottery. Thus, new data will be contributed to the discussion, raised (Olivera, 1992; 1997), about the region from which the influence that led to the Aguada presence in Antofagasta de la Sierra during the Middle and Late Formative period (2000 to $1100 \mathrm{BP}$ ) came, while analyzing the particular characteristics of Aguada in Antofagasta de la Sierra.
\end{abstract}

Keywords: Aguada pottery, technology, style, Puna, Formative period.

Recibido: 28 marzo 2018. Aceptado: 31 julio 2020 


\section{Introducción}

En la microrregión de Antofagasta de la Sierra (ANS) la cerámica está presente, por lo menos, desde momentos iniciales del Formativo (ca. $3000 \mathrm{AP}$ ). A partir de ca. 2000 AP (Formativo Tardío) aparece en la cerámica decorada mayor cantidad de fragmentos estilísticamente asociados a Saujil, Ciénaga y Aguada. Esta alfarería es similar a la de los valles ubicados al sur y al este de ANS, específicamente los valles de Abaucán y Hualfín (Olivera, 1992). La influencia de los valles en las poblaciones antofagasteñas se refleja además en otros aspectos de la sociedad, como el arte rupestre, la importancia cada vez mayor que adquiere la agricultura en la subsistencia y en el aumento de la población a nivel regional (Olivera y Podestá, 1993).

Algunos de los fragmentos cerámicos provenientes del sitio Casa Chávez Montículos (CChM) ya habían sido identificados como pertenecientes a Aguada en trabajos previos por sus características decorativas e iconográficas (Olivera, 1992; 1997). Estos atributos llevaron a Olivera a considerar que la aparición de Aguada en la Puna de Catamarca, junto con alfarería Saujil y Ciénaga, fue producto de la influencia de grupos humanos provenientes del valle de Abaucán. Dicha influencia se esperaría verla, además, en las características tecnológicas de la cerámica, especialmente si se considera que estos atributos forman parte de los entendimientos compartidos acerca de formas de hacer las cosas (Lemmonier, 1993) que se extendieron desde los valles a la puna. Hay atributos tecnológicos involucrados en la manufactura de vasijas, como la cocción y el procesamiento de la arcilla, en los que los cambios ocurren infrecuentemente $y$, en definitiva, estas técnicas deben reflejar redes de interacción locales o regionales (Gosselain, 2000).

Por lo tanto, con el objetivo de identificar de manera más precisa el posible valle relacionado con el fenómeno Aguada en ANS, en este trabajo se llevó a cabo una caracterización de las propiedades tecnológicas y decorativas de la cerámica Aguada hallada en la microrregión de ANS para el Período Formativo. Se consideraron para el análisis las características de tipo de pasta, tratamiento de superficie, atmósfera de cocción y técnicas decorativas. Los resultados fueron comparados con los datos, referentes a las mismas variables, obtenidos de la cerámica Aguada de los Valles de Abaucán y de Hualfín por otros autores (Sempé, 1976; Sempé y Albeck, 1981; Sempé, 1998; Sempé y Baldini, 2005; Zagorodny, Balesta, Avalos, Valencia y Gómez Ferreiro, 2005; Balesta, Zagorodny y Valencia, 2009; Feely, 2013). Esta comparación permitió avanzar en la comprensión del Período Formativo Tardío en ANS, más específicamente en el entendimiento de las vías de acceso seguidas por la influencia valliserrana en la puna de Catamarca durante el proceso.

Asimismo, se espera que los resultados del trabajo aporten al conjunto de los estudios tecnológicos sobre material cerámico Aguada en otras zonas, dentro de la denominada "región Aguada" (Acevedo et al., 2015). Esta abarcaría la región valliserrana, desde el norte de la provincia de San Juan hasta el sur de la provincia de Salta, manifestándose con características propias en cada zona de acuerdo con los procesos históricos locales (Callegari, Spengler y Rodríguez, 2015). El fenómeno Aguada se extendió incluso a la región de San Pedro de Atacama en el norte de Chile, donde fueron hallados cestos bordados, textiles y keros con diseños Aguada, figuras antropomorfas hechas en madera y cerámica pintada en rojo y negro sobre rojizo (Berenguer, 1984; Tarragó, 1989). La aparición de Aguada en esta región sucede estimativamente durante la denominada Fase Coyo (ca. 500 a 850 DC) y puede considerarse como exclusiva de enterramientos de élite, ya que se limita a material hallado en contextos funerarios y solo en algunas tumbas (Llagostera, 1995).

Los sitios con cerámica Aguada en ANS son bastante numerosos y se ubican tanto en el Fondo de Cuenca (3400-3500 msnm) como en las quebradas tributarias (3550-3900 msnm), e incluso en cotas aún más altas. Entre ellos se encuentran: Casas Viejas A y B y Casa Chávez Lomas (cementerios, Fondo de Cuenca); Río Miriguaca 1 y 2 (Puestos Agropastoriles, Sectores Intermedios), así como algunos sitios de la Quebrada de Calalaste (sector Campo Cortaderas), de Quebrada Río Las Pitas y de Antofalla (Las Queñoas y Botijuela), entre los más destacados (Olivera, 1997; Olivera, Elías, Pérez y Salminci, 2015). Sin embargo, se trata hasta el momento de contextos de superficie sin fechados radiocarbónicos asociados. 
Por ello, nos focalizaremos aquí en la cerámica de tipo Aguada ubicada en contextos estratigráficos fechados de Casa Chávez Montículos (Fondo de Cuenca). Si bien los resultados que se discuten en este trabajo se consideran de carácter preliminar, ya que provienen de una muestra relativamente pequeña, creemos que revisten cierta importancia por ser los primeros obtenidos y analizados sistemáticamente para esta región particular y para la puna argentina en general.

\section{Región de estudio y el sitio Casa Chávez Montículos}

Antofagasta de la Sierra se encuentra ubicada en el extremo noroeste de la provincia de Catamarca, Argentina. Corresponde a un sector importante de la Puna Meridional Argentina, un ambiente caracterizado por la variabilidad climática de corto plazo y por ser altamente impredecible, lo cual influye en los recursos naturales, en la producción agropecuaria y, consecuentemente, en el abastecimiento humano (Olivera, 1998).

Olivera (1992) distinguió en la microrregión tres sectores con media/alta concentración de recursos: a) Fondo de Cuenca (3400 a $3500 \mathrm{msnm}$ ), b) Sectores Intermedios (3550 a $3900 \mathrm{msnm})$ y c) Quebradas de Altura (3900 a $4600 \mathrm{msnm}$ ). Estos tres sectores presentan diferencias ecológicas, topográficas y de oferta de recursos faunísticos, vegetales y líticos/minerales (Olivera y Podestá, 1993). A lo largo del tiempo de ocupación humana de ANS, la forma de aprovechamiento de estos diferentes sectores fue variando en la medida que ocurrían cambios medioambientales, así como en los sistemas de subsistencia, de movilidad y ocupación del espacio y en la organización sociopolítica de los grupos humanos (Olivera, 2006).

El sitio Casa Chávez Montículos (CChM) está ubicado en el Fondo de Cuenca de ANS (3450 msnm). Se compone de 10 (diez) estructuras monticulares de carácter artificial y de la excavación de dos de las cuales $(1$ y 4$)$ proviene la muestra analizada (Figura 1). En el Montículo 1, sobre la base de diferencias en el carácter de los sedimentos y en la distribución de las áreas de actividad, se pudieron distinguir dos componentes de ocupación, uno inferior correspondiente al Formativo Temprano y otro superior asociado al Formativo Tardío. El registro del Montículo 4 corresponde en su totalidad a este último.

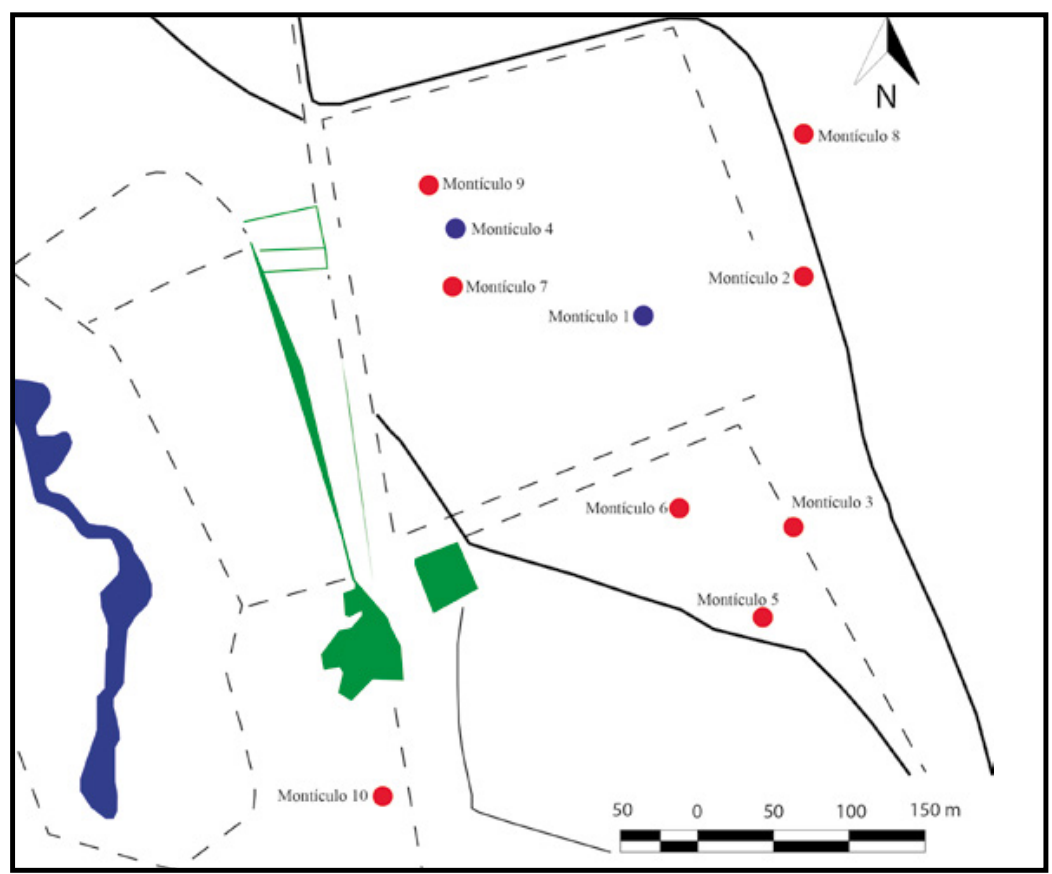

Figura 1. Esquema de la distribución de estructuras monticulares en CChM. Tomado y modificado de Olivera 1992. 
Según Olivera (1992), CChM consistió en una aldea ocupada de forma permanente y a lo largo de todo el ciclo anual. Fueron halladas estructuras de basural, de combustión, de cavado artificial, sectores de talla lítica, evidencias de fabricación de cerámica y registro de procesamiento y consumo de camélidos, todas evidencias que permitieron interpretar al asentamiento como una base residencial de actividades múltiples.

\section{Antecedentes de estudio en el área}

El Período Formativo en la microrregión de ANS fue definido para el lapso entre ca. 3000 y 1100 años AP. Durante esta etapa del proceso de ocupación humana de ANS, surgieron modos de subsistencia mixtos, basados en el pastoreo de camélidos (especialmente llama) complementado con la agricultura (posiblemente de maíz, quinoa y tubérculos), la caza y la recolección vegetal. De hecho, en CChM se identificaron restos quemados de Zea mays y dos especies de algarrobo (Prosopis alba y Prosopis chilensis). El sistema de asentamiento y movilidad consistió en bases residenciales de ocupación anual, como es el caso de la aldea CChM, ubicadas en el Fondo de Cuenca y en los sectores bajos/medios de las quebradas subsidiarias, sectores aptos para las prácticas de pastoreo de veranada y producción agrícola (Olivera et al., 2015). En el curso inferior a medio del río Las Pitas, ubicado en los Sectores Intermedios, hay registros de ocupaciones prolongadas y estables, como es el caso de Punta de la Peña 9, sitio caracterizado como una base residencial multicomponente cuya ocupación se inicia hacia $1970 \pm 50$ años ${ }^{14} \mathrm{C}$ AP (López Campeny, 2001; Cohen, 2005; Babot et al., 2006). Estos asentamientos se integraban con sitios de ocupación temporaria donde se realizaban actividades de caza, pastoreo y extracción de materias primas (minerales y líticas), ubicados en los Sectores Intermedios altos y en las Quebradas de Altura (Olivera, 1988).

Este período, a partir de ca. 3200 AP, se caracterizó por la aparición de nuevas tecnologías. Además de la metalurgia e innovaciones en la textilería, destaca la cerámica, tanto decorada como no decorada. Fragmentos cerámicos fueron hallados tanto en sitios del Fondo de Cuenca como en asentamientos ubicados a mayor altura. En los primeros momentos de ocupación de CChM (ca. 2400 a 2000 AP), correspondientes al Formativo Temprano, aparece con mayor frecuencia cerámica similar a la hallada en los sitios Tulor 1 y Turi del Norte de Chile (Llagostera, Barón y Bravo, 1984; Aldunate et al., 1986). Pero a partir de los 2000 AP y hasta el fin de la ocupación de la aldea en torno a los 1300 AP, ya en el Formativo Tardío, la cerámica de tipo Saujil, Ciénaga y Aguada, similar a la de los valles mesotermales de Argentina, ubicados al sur y al este, comienza a dominar en la cerámica decorada (Olivera, 1992). Específicamente, los fragmentos Aguada aparecen en los niveles más tardíos de la ocupación del sitio, es decir, en el componente superior del Montículo 1 y en el Montículo 4.

El incremento en la frecuencia de estas tipologías alfareras a partir del Formativo Tardío en la microrregión se da de forma contemporánea al incremento de la importancia que cobra la agricultura en la subsistencia de las poblaciones humanas (Olivera y Vigliani, 2000-2002) y a un aumento poblacional, observable en el mayor número de sitios asignados a este período y hallados en todos los microambientes de la cuenca (Escola et al., 2013; Olivera et al., 2015). Este proceso, de acuerdo con Olivera (1992), se relaciona con el establecimiento de vínculos más estrechos con los grupos valliserranos, específicamente de los valles de Hualfín y Abaucán. Por lo tanto, esta cerámica Aguada, así como la alfarería tipo Ciénaga y Saujil, comienza a reemplazar al temprano componente chileno, un indicio de las influencias de poblaciones provenientes de los valles sobre los grupos de pastores/agricultores que habitaban la puna durante el Formativo (Olivera, 1992).

Esta presencia de elementos valliserranos también se observa en el oasis de Laguna Blanca (Albeck y Scattolin, 1984), cercano a ANS. Sin embargo, Olivera (1992) considera que los elementos iconográficos y decorativos en los tipos cerámicos preponderantes en el Formativo Tardío de ambos oasis permiten pensar que se debieron a influencias desde diferentes valles. De esta forma la cerámica de CChM y otros sitios de ANS se acerca más a los tipos cerámicos característicos del valle de Abaucán, mientras que Laguna Blanca parece haber sido influida principalmente por las poblaciones del valle de Hualfín (Figura 2). 


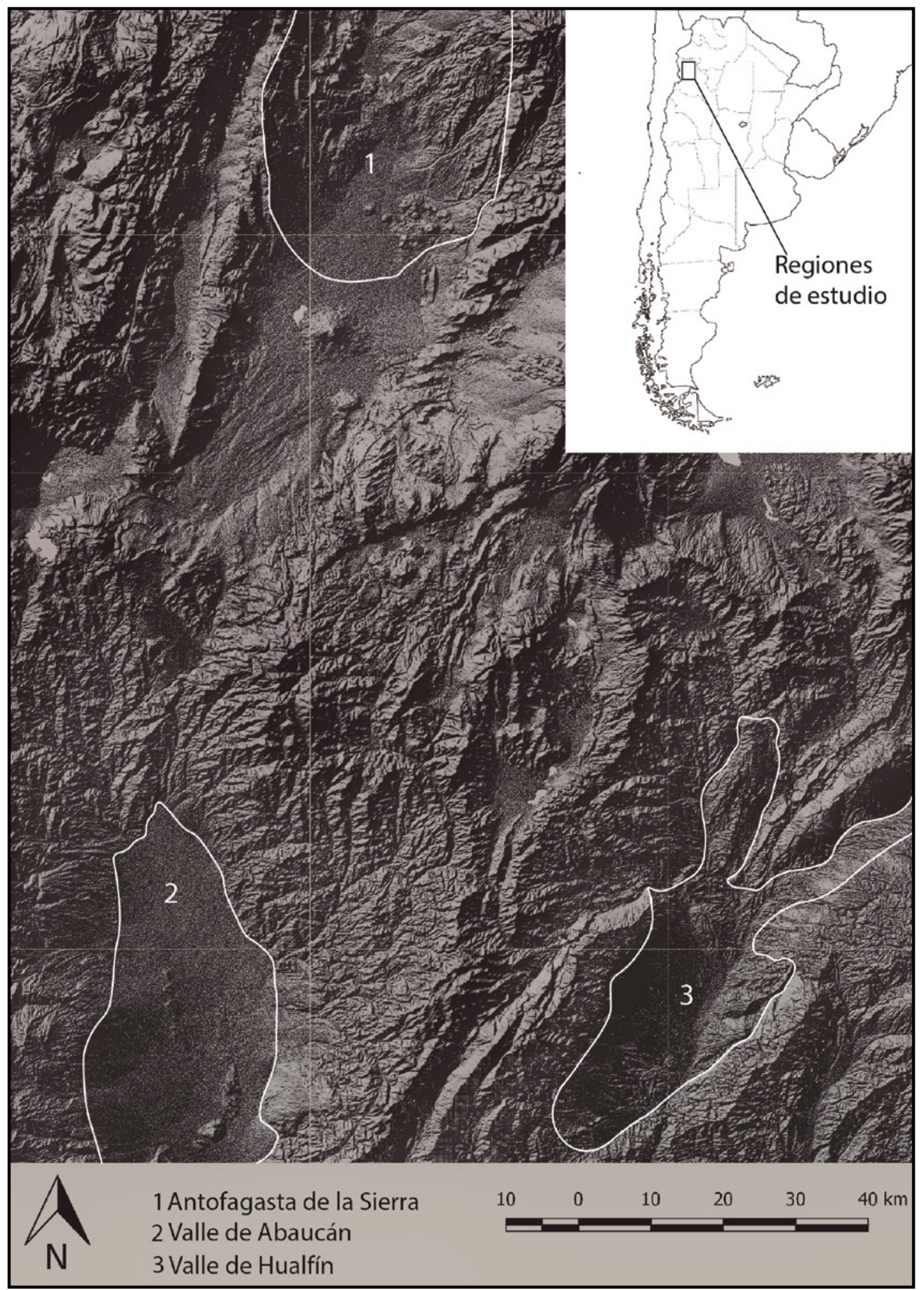

Figura 2. Mapa con las regiones de estudio mencionadas. 


\section{Marco teórico-metodológico}

La muestra cerámica fue definida luego de identificar los fragmentos como Aguada a partir de sus estilos decorativos y consta de 27 piezas. Estas fueron recuperadas de los niveles I a V de los Montículos 1 y 4 del sitio CChM, proviniendo 21 (veintiún) fragmentos del Montículo 1 y 6 (seis) del Montículo 4 .

Se considera que las técnicas que intervienen en las prácticas de producción de artefactos, incluyendo la alfarería, resultan de la materialización de elecciones y esquemas mentales enseñados y aprendidos a través de una tradición tecnológica. A su vez, estas tradiciones están inmersas en un entramado sociocultural que impone un control sobre las elecciones técnicas, dándose de esta forma la transmisión de un conocimiento social (Trías y García Roselló, 2012). En ese sentido, la manufactura de bienes cerámicos se da dentro de un número limitado de posibilidades que se repiten y reproducen a través del tiempo. Así, las elecciones que se dan en los diferentes pasos de la cadena operativa que intervienen en la manufactura cerámica tenderán a variar poco a través del tiempo, dando lugar a una determinada manera de hacer las cosas, propia de una tradición alfarera (Lemmonier, 1993). En definitiva, ello permitiría identificar a un grupo particular, los contactos entre comunidades a través del proceso productivo y la transmisión del conocimiento técnico.

La secuencia de producción alfarera consiste en varias etapas, cada una de las cuales otorga al alfarero la posibilidad de elegir entre diferentes opciones técnicas alternativas (Rice, 1987). Las variables tecnológicas y decorativas de la cerámica arqueológica, como son la atmósfera de cocción, la granulometría y el grado de compactación de la pasta, el tratamiento de superficie y las técnicas decorativas, son el resultado de estas diferentes etapas productivas y, como tales, permiten evaluar cuáles de las diferentes opciones disponibles fueron adoptadas por los alfareros del pasado durante el proceso de producción.

Para este trabajo se tomó como referencia el aporte de Feely (2013) para definir las cuatro variables de análisis:
1. Atmósfera de cocción. El momento de la cocción cerámica es la etapa más compleja del proceso de manufactura y por ello el grado de desarrollo técnico cerámico de la comunidad alfarera determinará el tipo de cocción utilizada. La atmósfera a la que están sometidos los objetos depende de la cantidad de aire en circulación durante el momento de cocción, dando lugar a atmósferas oxidantes, reductoras o mixtas (García Roselló y Trías, 2006). Para inferir los tipos de atmósferas a los que fueron sometidas las piezas, se recurrió a la observación macroscópica de la secuencia cromática en el corte transversal de los fragmentos (Rye, 1981). Se considera que estas observaciones resultan válidas para aproximarse a un entendimiento del sistema de cocción, que abarca el tipo de atmósfera de cocción, el tipo de estructura de combustión utilizada y la posición de la vasija dentro de dicha estructura. De esta forma, en el corte transversal de las paredes se observó la coloración del núcleo, de los márgenes adyacentes a este y el color de la superficie, que además es indicativo del tipo de estructura de cocción utilizada y de la posición de la pieza (García Roselló y Trías, 2006). Debido a que el color de la pasta cerámica también viene determinado por la presencia de materia orgánica y hierro (Rice, 1987), se tuvo en cuenta en el análisis la presencia o ausencia de este tipo de impurezas en la pasta.

2. Grado de compactación de la pasta. Se observaron las características del antiplástico (tamaño, tipo y porcentaje) a través de lupa binocular de bajos aumentos (20X) y de la estructura de la matriz arcillosa a ojo desnudo, para definir las texturas de las pastas diferenciando entre textura fina y textura mediano-gruesa. Los resultados fueron clasificados tomando como referencia la caracterización de las pastas realizada por Feely (2013) para la cerámica de las regiones de Chaschuil y Abaucán, cercanas geográficamente y relacionadas culturalmente con nuestra región.

3. Tratamiento de superficie. Uno de los últimos pasos en el proceso de manufactura cerámica es el acabado de superficie, que implica el uso de herramientas para modificar las características de la superficie de las vasijas (Rice, 1987). Se registraron diferentes tratamientos de superficie, tanto para la 
superficie externa como interna de los fragmentos, distinguiendo entre dos categorías (alisado y pulido) y diferentes variantes dentro de cada una de ellas, a partir de la textura de la superficie, el total de superficie cubierta por el tratamiento y el carácter de las líneas de alisado o pulido.

4. Técnica decorativa. La última variable considerada refiere a las técnicas utilizadas para modificar el aspecto de la superficie de las vasijas, más allá de las técnicas de acabado de superficie, para dar forma a motivos iconográficos, tanto figurativos como no-figurativos. Se distinguieron dos técnicas, desplazamiento de materia y agregado de pigmentos. Esta última categoría fue a su vez dividida en diferentes variantes, en función de los colores utilizados y su disposición.

Una vez analizadas estas variables de la cerámica, se procedió a comparar los resultados con los datos obtenidos por otras investigaciones (Sempé, 1976; Sempé y Albeck, 1981; Sempé, 1998; Sempé y Baldini, 2005; Zagorodny et al., 2005; Balesta et al., 2009; Feely, 2013), acerca de las características tecnológicas y decorativas de la cerámica Aguada de los valles de Hualfín y Abaucán.

Hay algunos elementos, como la atmósfera de cocción y el grado de compactación de la pasta, que aquí consideramos relacionados con determinados procesos tecnológicos, que están fuertemente enraizados en las tradiciones tecnológicas de una comunidad, lo cual les confiere resistencia al cambio a través del tiempo y el espacio. Así, refieren a aspectos de la cadena operativa de producción con una menor maleabilidad técnica, debido a que los comportamientos productivos no pueden ser leídos directamente en el producto terminado (Gosselain, 2000). Además, la transmisión de los conocimientos técnicos asociados a estas variables se basa en la cercana interacción entre maestro y aprendiz (Trías y García Roselló, 2012). Por lo tanto, estos aspectos de la cerámica arqueológica pueden ser indicativos de la identidad de una comunidad alfarera específica, que puede tener una extensión geográfica limitada. La tercera y cuarta variable, el tratamiento de superficie y la técnica decorativa, a las que referiremos como procesos técnico-gestuales, reflejan etapas que tienen una mayor tendencia a fluctuar a través del tiempo y el espacio, en tanto son más fácilmente transmisibles por interacciones posteriores al aprendizaje y en definitiva son más maleables. De esta forma, estilos decorativos particulares pueden abarcar un área geográfica amplia, en tanto constituyen variaciones estéticas que son más fáciles de adoptar y no implican profundos cambios en el "saber hacer" de la sociedad que los adopta (Trías y García Roselló, 2012).

Por lo tanto, se considera que los procesos tecnológicos presentes en la cerámica Aguada de ANS podrían mostrar una continuidad respecto a las técnicas de manufactura de cerámica existentes desde el Formativo Temprano en la microrregión. Asimismo, es más probable que los procesos técnico-gestuales adquieran valores simbólicos, estéticos y/o económicos y tiendan a ser imitados o modificados intencionalmente (Chilton, 1999). Por ello, podríamos esperar que muestren una continuidad en relación al valle o valles que incidieron en la introducción de la alfarería Aguada en ANS durante el Formativo Tardío. En definitiva, el aspecto iconográfico de la cerámica analizada podría mostrar similitudes entre regiones, al tiempo que los atributos tecnológicos podrían ser diferentes.

\section{Resultados}

La variable atmósfera de cocción se analizó teniendo en cuenta la secuencia cromática de la pasta, a partir de lo cual se identificaron seis secuencias cromáticas, que corresponden a tres atmósferas generales de cocción. La muestra está dominada por fragmentos sometidos a cocción reductora, especialmente sin variación cromática en el corte transversal. Los tipos de cocción oxidante y mixto aparecen menos representados, dominando entre los fragmentos oxidantes aquellos que no presentan variación cromática (Tabla 1). A un nivel general de la muestra, observamos que no existe una estandarización en las secuencias cromáticas, presentándose destacada variabilidad (Figura 3). Esto es indicativo de que no hubo un alto grado de homogeneidad técnica en lo que refiere a esta etapa del proceso de producción cerámica y por lo tanto no se dio una alta estandarización en los aspectos de la cocción que inciden en la secuencia cromática (atmósfera de cocción, tipo de estructura de combustión y posición de la vasija durante la cocción). 
Tabla 1. Características de las secuencias cromáticas.

\begin{tabular}{|c|c|c|}
\hline Tono & Atributos & Tipo de cocción \\
\hline \multirow{3}{*}{$\begin{array}{l}\text { Anaranjado / rojizo } \\
(\mathrm{n}=8) 2.5 \mathrm{YR} 6 / 8- \\
\quad 5.0 \text { YR 5/6 }\end{array}$} & Sin diferencias cromáticas $(5: 27)$ & \multirow{3}{*}{ Oxidante } \\
\hline & Diferencias cromáticas en el núcleo (1:27) & \\
\hline & Diferencias en parte de una o ambas superficies (2:27) & \\
\hline \multirow{3}{*}{$\begin{array}{c}\text { Grises a negras }(n=12) \\
2.5 \mathrm{G} 5 / 2-2.5 \mathrm{BG} 3 / 2- \\
2.5 \mathrm{~B} 8 / 2\end{array}$} & Sin diferencias cromáticas $(9: 27)$ & \multirow{3}{*}{ Reductora } \\
\hline & Diferencias cromáticas en el núcleo (2:27) & \\
\hline & Diferencias cromáticas en las superficies (1:27) & \\
\hline Incompleto $(\mathrm{n}=7)$ & Diferencias cromáticas entre núcleos, márgenes y superficies (7:27) & Mixta \\
\hline
\end{tabular}

En la columna Tono se incluyen los valores asignados por la Tabla de Colores Munsell.

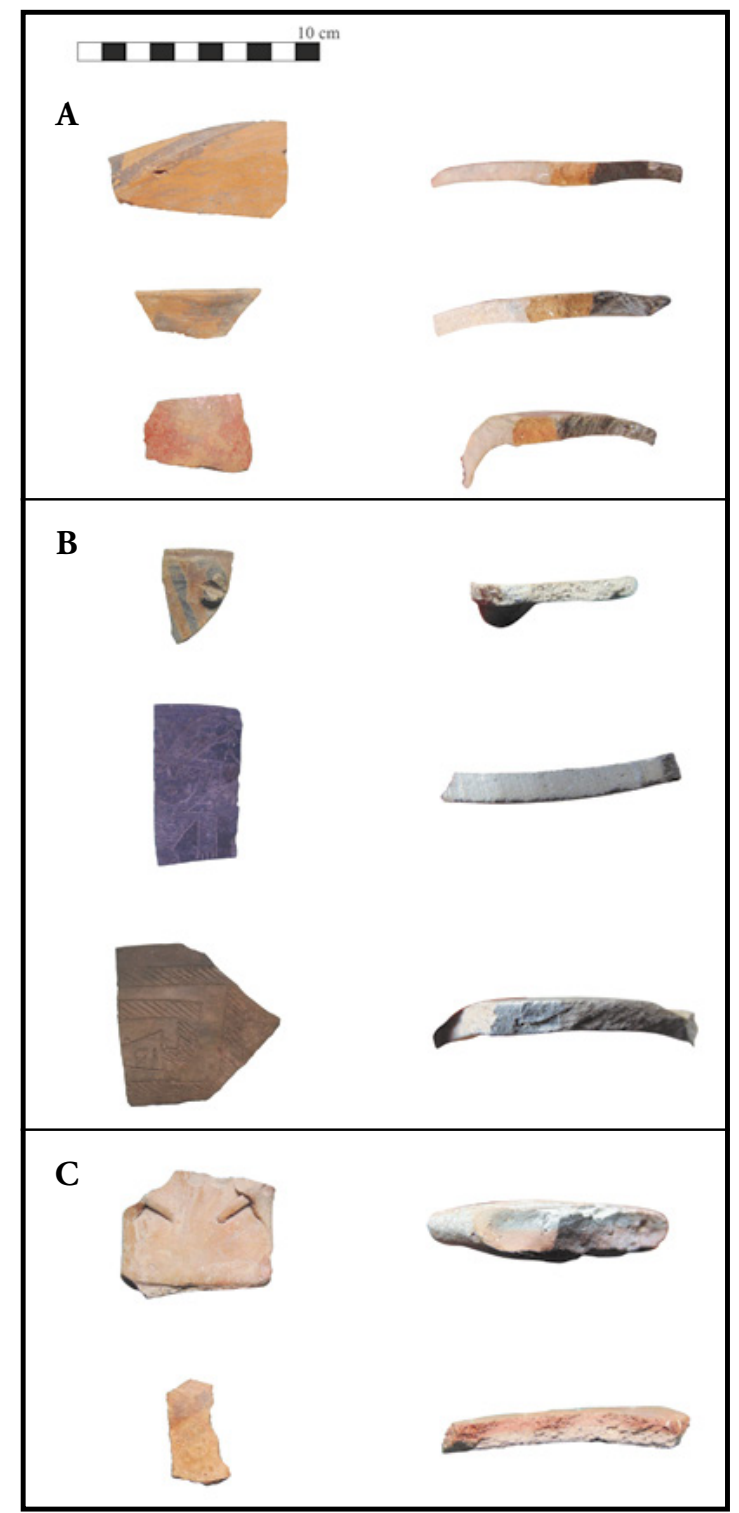

Figura 3. Cortes frescos representativos de los tres tipos de cocción.

A. Tipo de cocción oxidante. B. Tipo de cocción reductor. C. Tipo de cocción mixto. 
La muestra está ampliamente dominada por pastas de textura muy fina o fina (Grupo I), en las cuales las inclusiones no sobrepasan los $0,8 \mathrm{~mm}$ de tamaño, y cuando lo hacen, se trata de antiplásticos aislados. Los restantes tipos de pastas que aparecen (Grupos II y III) se presentan en bajas proporciones (Tabla 2). Para los tres grupos reconocidos, los tipos de inclusiones que se pudieron identificar con una lupa binocular de bajo aumento coinciden, aunque varían en sus tamańos, predominando el basalto y el cuarzo y en menor medida la mica y rocas blancas.
Sin embargo, logramos reconocer diferencias en la cuantificación de antiplásticos entre grupos, ya que el promedio de abundancia aproximada en el Grupo 1 es de 7,8\%, en el Grupo 2 es de 12,9\% y en el Grupo 3 es del 20\%, si bien en este último se trata de un solo caso, por lo cual puede no ser representativo (Tabla 3). Sin duda estas diferencias inciden en los distintos tipos de texturas definidas, aunque debemos recalcar que estos resultados aproximados son de carácter preliminar y serán perfeccionados con análisis petrográficos aún en proceso.

Tabla 2. Características de los grupos de pasta.

\begin{tabular}{|c|c|c|}
\hline \multirow{2}{*}{$\begin{array}{c}\text { Grupo de } \\
\text { Pasta }\end{array}$} & Textura & Matriz \\
\cline { 2 - 3 } & Porosidad \\
\hline I $(\mathrm{n}=20)$ & Muy fina/fina & Ligeramente porosa/sin poros \\
\hline II $(\mathrm{n}=6)$ & Media & Ligeramente porosa/media \\
\hline III $(\mathrm{n}=1)$ & Gruesa & Media/porosa \\
\hline
\end{tabular}

Tabla 3. Antiplásticos identificados, su abundancia y tamaño por Grupo de Pasta.

\begin{tabular}{|c|c|c|c|c|}
\hline Fragmento & Antiplásticos identificados & Abundancia aproximada & Tamańo & Grupo de pasta \\
\hline 741 & Basalto y cuarzo & $5 \%$ a $10 \%$ & $0,08 \mathrm{~mm}$ a $1 \mathrm{~mm}$ & I \\
\hline 172 & Basalto y cuarzo & $25 \%$ & $0,08 \mathrm{~mm}$ a $0,6 \mathrm{~mm}$ & $\mathrm{I}$ \\
\hline $242 / 5811$ & Basalto y mica & $20 \%$ & $0,08 \mathrm{~mm}$ a $0,4 \mathrm{~mm}$ & I \\
\hline 2413 & Basalto, cuarzo y rocas blancas & $10 \%$ & $0,08 \mathrm{~mm}$ a $0,8 \mathrm{~mm}$ & I \\
\hline 491 & \multicolumn{3}{|c|}{ No identificados } & I \\
\hline 5063 & Cuarzo y mica & $10 \%$ & $0,08 \mathrm{~mm}$ a $0,4 \mathrm{~mm}$ & I \\
\hline 5210 & \multicolumn{3}{|c|}{ No identificados } & I \\
\hline $185 / 3340$ & Basalto y mica & $10 \%$ & $0,08 \mathrm{~mm}$ a $1 \mathrm{~mm}$ & I \\
\hline 5281 & Cuarzo, mica y rocas no identificadas & $10 \%$ a $20 \%$ & $0,08 \mathrm{~mm}$ a $1,2 \mathrm{~mm}$ & I \\
\hline 601 & \multicolumn{3}{|c|}{ No identificados } & I \\
\hline 181 & Feldespatos e inclusiones blancas & $1 \%$ & $0,08 \mathrm{~mm}$ & I \\
\hline 168 & Basalto y mica & $5 \%$ & $0,08 \mathrm{~mm}$ a $0,8 \mathrm{~mm}$ & I \\
\hline 415 & Basalto, cuarzo y mica & $10 \%$ & $0,08 \mathrm{~mm}$ a $2 \mathrm{~mm}$ & I \\
\hline 193 & Basalto y mica & $10 \%$ & $0,08 \mathrm{~mm} 0,8 \mathrm{~mm}$ & I \\
\hline 419 & Basalto e inclusiones blancas & $5 \%$ & $0,08 \mathrm{~mm}$ a $0,2 \mathrm{~mm}$ & I \\
\hline 2220 & Basalto, mica e inclusiones blancas & $10 \%$ & $0,08 \mathrm{~mm}$ a $1,6 \mathrm{~mm}$ & I \\
\hline 21240 & Feldespatos y mica & $5 \%$ & $0,08 \mathrm{~mm}$ a $0,2 \mathrm{~mm}$ & I \\
\hline 18b1 & Basalto, cuarzo y mica & $10 \%$ & $0,08 \mathrm{~mm}$ a $0,48 \mathrm{~mm}$ & I \\
\hline 3 & Basalto y mica & $1 \%$ & $0,08 \mathrm{~mm}$ & $\mathrm{I}$ \\
\hline $2150(2)$ & Rocas blancas & $1 \%$ & $2 \mathrm{~mm}$ a $4 \mathrm{~mm}$ & $\mathrm{I}$ \\
\hline 1682 & Cuarzo, mica y rocas no identificadas & $5 \%$ & $0,08 \mathrm{~mm}$ a $0,4 \mathrm{~mm}$ & II \\
\hline 1905 & Basalto y cuarzo & $10 \%$ & $0,08 \mathrm{~mm}$ a $1,2 \mathrm{~mm}$ & II \\
\hline 257616 & Cuarzo, mica y rocas & $25 \%$ & $0,08 \mathrm{~mm}$ a $2,1 \mathrm{~mm}$ & II \\
\hline 421 & Mica y rocas blancas & $5 \%$ & $0,08 \mathrm{~mm}$ a $0,32 \mathrm{~mm}$ & II \\
\hline 497 & Basalto, cuarzo y mica & $10 \%$ & $0,08 \mathrm{~mm}$ a $1,2 \mathrm{~mm}$ & II \\
\hline $78 / 2110$ & Basalto, cuarzo, mica y feldespatos & $20 \%-25 \%$ & $0,08 \mathrm{~mm}$ a $2 \mathrm{~mm}$ & II \\
\hline 4956 & Cuarzo y mica & $20 \%$ & $0,08 \mathrm{~mm}$ a $2 \mathrm{~mm}$ & III \\
\hline
\end{tabular}


La tercera variable, el tratamiento de superficie, muestra una preponderancia de la técnica de pulido. El pulido regular completo, el tratamiento de superficie más cuidadoso, es el más frecuente entre ambas superficies, aunque también aparecen recurrentemente fragmentos con la superficie pulida de forma incompleta, o pulidos completamente, pero con marcas de pulido notorias (Tabla 4).

Por último, se consideraron las técnicas decorativas, de entre las cuales la adición de pigmentos es la mayoritaria. La incisión de línea compuesta es la segunda técnica más representada, mientras la combinación de pintura con incisiones y con pastillaje, la menos frecuente (Figura 4).

Entre las variantes del agregado de pintura, dos son las más representadas: el negro sobre engobe coloreado y el negro sobre superficie color natural $(n=8$, cada una). La pintura roja sobre natural también está muy presente $(n=5)$, aunque en menor medida que las dos anteriores (Figura 5).

Tabla 4. Variantes del tratamiento de superficie.

\begin{tabular}{|c|c|c|c|c|}
\hline \multicolumn{5}{|c|}{ Tratamiento de superficie } \\
\hline \multirow{2}{*}{ Categoría } & Variante & $\begin{array}{c}\text { Textura } \\
\text { de la superficie }\end{array}$ & $\begin{array}{c}\text { Cobertura } \\
\text { de la superficie }\end{array}$ & $\begin{array}{c}\text { Líneas de alisado } \\
\text { y pulido }\end{array}$ \\
\hline Alisado & $\mathrm{A}(\mathrm{n}=1)$ & Irregular & Completa & Muy marcadas \\
\hline \multirow{3}{*}{ Pulido } & $\mathrm{A}(\mathrm{n}=1)$ & Irregular & Incompleta & Muy marcadas \\
\cline { 2 - 5 } & $\mathrm{B}(\mathrm{n}=7)$ & Regular & Incompleta & Muy marcadas \\
\cline { 2 - 5 } & $\mathrm{C}(\mathrm{n}=6)$ & Regular & Completa & Muy marcadas \\
\cline { 2 - 5 } & $\mathrm{D}(\mathrm{n}=12)$ & Regular & Completa & Levemente marcadas \\
\hline
\end{tabular}

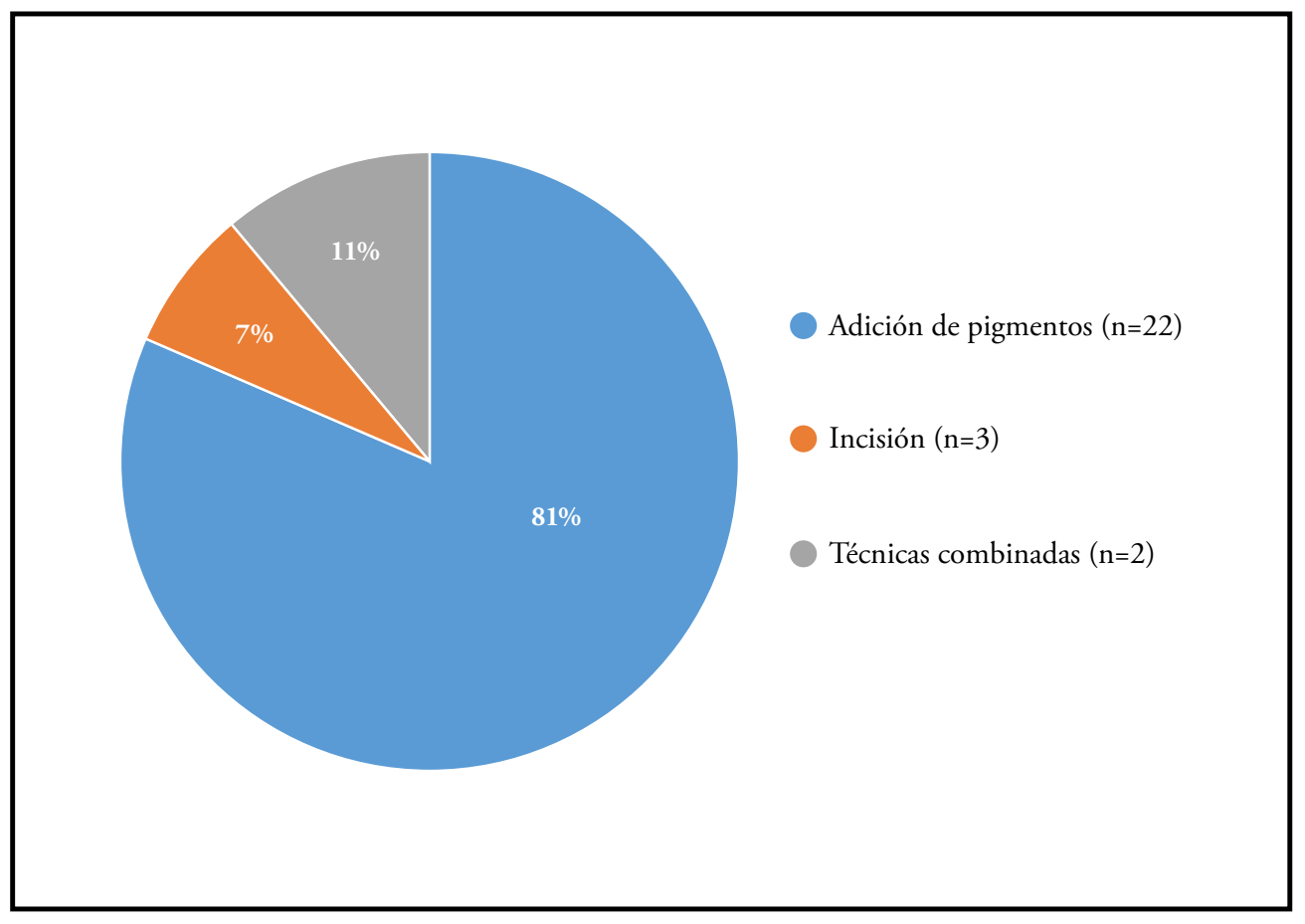

Figura 4. Técnicas decorativas. 
Incisión de línea compuesta

Adición de pigmentos (engobe coloreado) e incisión

Adición de pigmentos (engobe coloreado) y agregado de materia

Adición de pigmentos (negro sobre engobe coloreado)

Adición de pigmentos (negro y rojo sobre natural)

Adición de pigmentos (rojo sobre natural)

Adición de pigmentos (negro sobre natural)
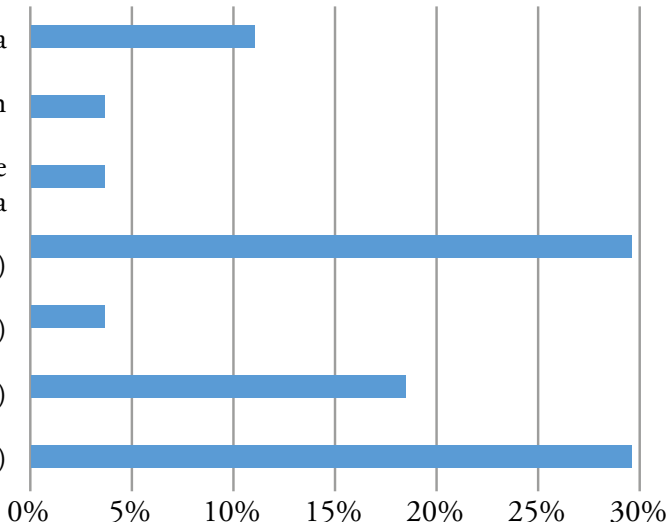

Figura 5. Variantes de las técnicas decorativas.

Tabla 5. Dataciones radiocarbónicas y calibraciones realizadas en Casa Chávez Montículos y sitios del valle de Abaucán (Palo Blanco, El Zorro y Punta Colorada).

\begin{tabular}{|c|c|c|c|c|c|c|}
\hline Sitio & U. estratigráfica & Laboratorio & $\begin{array}{l}\text { Código del } \\
\text { laboratorio }\end{array}$ & ${ }^{14} \mathrm{C}$ Fecha & $\begin{array}{c}\text { Fechado calibrado } \\
\text { (1 sigma) }\end{array}$ & $\begin{array}{l}\text { Ubicación } \\
\text { geográfica }\end{array}$ \\
\hline Palo Blanco & NH 5 H2: $1,55-1,65$ & LATYR (UNLP) & LP 362 & $1330+/-100 \mathrm{AP}$ & $603-777 \mathrm{cal} \mathrm{AD}$ & Valle Alto \\
\hline Palo Blanco & NH 5 H2: $1,35-1,45$ & LATYR (UNLP) & LP 354 & $1350+/-95 \mathrm{AP}$ & 594-773 cal AD & Valle Alto \\
\hline Palo Blanco & NH 5 H2: $1,45-1,55$ & LATYR (UNLP) & LP 334 & $1430+/-60 \mathrm{AP}$ & $575-657 \mathrm{cal} \mathrm{AD}$ & Valle Alto \\
\hline Palo Blanco & NH 5 H1 TE-0,60 & LATYR (UNLP) & LP 390 & $1520+/-70 \mathrm{AP}$ & $528-605 \mathrm{cal} \mathrm{AD}$ & Valle Alto \\
\hline Palo Blanco & NH 3 & NSF Arizona & AA 65138 & $1566+/-39 \mathrm{AP}$ & $458-535 \mathrm{cal} \mathrm{AD}$ & Valle Alto \\
\hline Palo Blanco & NH 6 & NSF Arizona & AA 81736 & $1197+/-37 \mathrm{AP}$ & $800-882 \mathrm{cal} \mathrm{AD}$ & Valle Alto \\
\hline Palo Blanco & $\mathrm{NH} 6$ & NSF Arizona & AA 81735 & $1236+/-37 \mathrm{AP}$ & $693-748 \mathrm{cal} \mathrm{AD}$ & Valle Alto \\
\hline El Zorro & Estructura 8 & NSF Arizona & AA 95554 & $1706+/-37 \mathrm{AP}$ & $322-392 \mathrm{cal} \mathrm{AD}$ & Puna \\
\hline El Zorro & Estructura $15 \mathrm{~b}$ & NSF Arizona & AA 89935 & $1604+/-49 \mathrm{AP}$ & $478-534 \mathrm{cal} \mathrm{AD}$ & Puna \\
\hline Punta Colorada & Sitio 1: 00-0,20 & LATYR (UNLP) & LP 433 & $1080+/-70 \mathrm{AP}$ & $887-1023 \mathrm{cal}$ AD & Valle Medio \\
\hline Punta Colorada & Sitio 2: HA & LATYR (UNLP) & LP 441 & $1240+/-90 \mathrm{AP}$ & $684-782 \mathrm{cal} \mathrm{AD}$ & Valle Medio \\
\hline Punta Colorada & Sitio 1: 040-050 & LATYR (UNLP) & LP 407 & $1250+/-70 \mathrm{AP}$ & $678-778 \mathrm{cal} \mathrm{AD}$ & Valle Medio \\
\hline Punta Colorada & Sitio 3: $0,00-0,20$ & LATYR (UNLP) & LP 372 & $1310+/-100 \mathrm{AP}$ & $640-778 \mathrm{cal} \mathrm{AD}$ & Valle Medio \\
\hline CChM 1 & Nivel III & BETA ANALYTIC & B 27199 & $1670+/-60 \mathrm{AP}$ & $320-427 \mathrm{cal} \mathrm{AD}$ & ANS \\
\hline CChM 1 & Nivel IV & LATYR (UNLP) & LP 251 & $1660+/-60 \mathrm{AP}$ & $326-430 \mathrm{cal} \mathrm{AD}$ & ANS \\
\hline CChM 1 & Nivel Vc & BETA ANALYTIC & B 27201 & $1530+/-70 \mathrm{AP}$ & $527-596 \mathrm{cal} \mathrm{AD}$ & ANS \\
\hline CChM 4 & Nivel V & BETA ANALYTIC & B 27198 & $1740+/-100 \mathrm{AP}$ & $168-195 \mathrm{cal} \mathrm{AD}$ & ANS \\
\hline
\end{tabular}

Tomado de Olivera, 1992; Gordillo, 1999; Kligmann, Ratto \& Maidana, 2013; Ratto, $2013 .{ }^{1}$

\section{La cerámica Aguada de los valles de Abaucán y Hualfín}

En el valle de Abaucán, Sempé (1998) observó que la ocupación Aguada se inicia aproximadamente entre 540 y 650 DC, durante la denominada fase Palo Blanco, dándose una dominación de Aguada sobre grupos de cultura Saujil. Esta época es coincidente con la ocupación final de la aldea CChM ya durante el Formativo Tardío de ANS, que es cuando aparece cerámica tipo Aguada en CChM (Tabla 5).

1 En el sitio Cuesta de Zapata se obtuvieron cuatro fechados radiocarbónicos correspondientes al Formativo Medio (de entre 140 y 250 DC) y asociados a cerámica Aguada. Sin embargo, no fueron incluidos en la Tabla 5 debido a la consideración de González de que son 
Volviendo a Abaucán, el proceso Aguada se observó en dos sitios (Punta Colorada y Palo Blanco) que presentan hallazgos correspondientes a la fase Palo Blanco (Sempé, 1976). En el sitio Punta Colorada, la cerámica asignada a Aguada se caracteriza por los motivos decorativos geométricos (por ejemplo, rombos) realizados mediante incisión o pintura en negro y rojo sobre ante. Las pastas para esta fase son gruesas, con superficies alisadas de color gris o ante, generalmente de cocción oxidante. En este sitio también aparece cerámica con la superficie interna negra pulida, siendo en algunos casos un pulido irregular que deja al descubierto un fondo alisado y en otros casos presenta un pulido de gran calidad, y la superficie externa color ante decorada con motivos lineales y geométricos pintados en negro (Sempé, 1976). Este tipo de cerámica, es decir, con el interior negro pulido, también aparece en Hualfín. En este caso los fragmentos son de cocción predominantemente oxidante, con superficies externas casi siempre pulidas y de color ante, decoradas con motivos figurativos (felinos o antropomorfos) pintados en negro o en rojo y negro (Sempé y Albeck, 1981).

En el sitio Palo Blanco, ubicado al noroeste del Bolsón de Fiambalá, la cerámica Aguada que aparece inicialmente es identificada ante todo por las formas de las piezas (piezas abiertas y compuestas en forma de pucos). En este sitio la cerámica Aguada inicial se caracteriza decorativamente por motivos geométricos escalonados compuestos, desarrollados principalmente mediante incisión sobre superficies grises, indicio de un tipo de cocción reductora. Las pastas son gruesas y los acabados de superficie predominantemente toscos e incompletos. También aparecen fragmentos de color ante o crema, decorados con pintura roja, negra o la combinación de ambos colores, formando casi siempre motivos geométricos. En solo un recinto del sitio los motivos son figurativos (felino con características de serpiente). Tanto para

fechados erróneos, ya que provienen de un nivel donde el material Aguada forma un palimpsesto con los restos de la cultura Saujil, anterior a la ocupación de la cultura Aguada (González y Cowgill, 1975). Sin embargo, en nuestra opinión no deberían ser descartados absolutamente hasta que se lleven adelante mayores investigaciones. También en nuestra región tenemos un fechado muy temprano en CChM 4 y aparentemente asociado a cerámica Aguada. la cerámica que presenta motivos geométricos como figurativos, Sempé (1976) sostiene que la manufactura es de carácter local, es decir, que posee superficies alisadas o pulidas y formas de la terminación de la pintura similares a los tipos Aguada que aparecen en La Rioja (Aguada Meridional), donde las vasijas se caracterizan generalmente por presentar pastas finas, muchas veces porosas, cocidas en atmósfera oxidante, decoradas con diseńos pintados en negro sobre superficies color natural o blanquecino, alisadas o pulidas (Acevedo et al., 2015). En términos generales se observa que la cerámica durante la fase Palo Blanco en Abaucán es predominantemente pintada en rojo o negro o la combinación de ambos colores sobre ante, crema o natural (Sempé, 1976).

En esta región, el fenómeno Aguada plenamente desarrollado no aparecerá hasta entre ca. 720 a 850 DC, durante la denominada Fase Montura del Gigante. En ella la cerámica Aguada presenta una mayor calidad tecnológica que en momentos anteriores y se desarrolla la iconografía figurativa (camélidos y felinos) pintada en negro sobre ante (Sempé, 1976).

Más recientemente Feely (2013), en el marco del Proyecto Arqueológico Chaschuil-Abaucán, llevó a cabo un análisis tecnológico-estilístico de la cerámica de varios sitios de la región del oeste tinogasteño, donde se encuentra el valle de Abaucán. Del total de fragmentos analizados, la autora pudo identificar 135 fragmentos Aguada. Estos se caracterizan por un tipo de pasta predominante de textura fina/ muy fina con escasa cantidad de antiplásticos y ligeramente porosa y de cocción mayoritariamente oxidante (cerca de un 70\%), mientras que en alrededor del 25\% se agrupan las piezas con cocción reductora u oxidante incompleta. En lo referente al tratamiento de superficie, tanto interno como externo, la cerámica Aguada de Tinogasta se caracteriza mayoritariamente por estar totalmente pulida y en menor medida alisada, presentando la superficie externa decoración principalmente pintada en rojo o rojo y negro sobre fondo natural y rojo y negro sobre engobe coloreado, apareciendo en menor medida el grabado y la incisión.

En el valle de Hualfín se puede observar que la cerámica Aguada presenta diferencias en las características tecnológicas e iconográficas respecto de la 
procedente de Abaucán. En este valle la aparición de Aguada ocurre en torno al 600 DC, momento en el que se produjo un contacto con desarrollos culturales previos (Sempé, 1998). En el cementerio La Aguada Orilla Norte, ubicado en un valle lateral al Hualfín, Sempé (1998), Zagorodny et al. (2005) y Balesta et al. (2009) llevaron a cabo análisis tecnológicos e iconográficos sobre las piezas (tanto enteras como fragmentadas) recuperadas. Aquí se observó que la atmósfera de cocción es predominantemente reductora. Así, 93 (noventa y tres) piezas son totalmente reductoras y solo una muestra márgenes más claros y el núcleo negro. Estas presentan superficies de color gris y están decoradas mediante incisiones. Las piezas con cocción totalmente oxidante son una cantidad considerablemente menor que aquellas reducidas: solo 20 (veinte) (Zagorodny et al., 2005; Balesta et al., 2009). En este caso la decoración consiste en pintura negra sobre fondo ante o rojizo. Para ambos tipos de cocción, de acuerdo con las autoras, la casi ausencia total de núcleo podría estar indicando un control efectivo en la etapa de cocción.

En cuanto al tratamiento decorativo, en este caso las vasijas fueron decoradas en su mayoría (72\%) mediante incisión sobre superficies grises, mientras que el $6 \%$ de las vasijas fueron pintadas. En esta técnica decorativa se registran tres variantes de las consideradas por Feely (2013): negro sobre fondo natural, que es la mayoritaria, y en menor medida se observa rojo sobre fondo natural y negro y rojo sobre fondo natural o sobre ante (Zagorodny et al., 2005). Respecto a los valores porcentuales de estas técnicas en Hualfín, no se dispone de datos (Tabla 6).
Los tratamientos de la superficie muestran diferencias entre la superficie externa y la interna de las vasijas analizadas. La primera se caracteriza por ser lisa y uniforme, mientras que la interna muestra irregularidades producto del proceso de manufactura (Zagorodny et al., 2005). Además, las superficies internas muestran variabilidad entre vasijas, ya que pueden presentar tanto un pulido irregular completo (pulido vertical y horizontal en las piezas de perfil compuesto) como regular completo muy marcado (pulido horizontal en las piezas de perfil simple). En esta cerámica, el pulido se aplicó como técnica de acabado de superficie final, posterior a la aplicación de la pintura, dando el mismo efecto de brillo en toda la superficie de la vasija.

La cerámica Hualfín muestra mayor presencia de motivos figurativos en su decoración que la de Abaucán, tanto grabados como pintados. Entre estos motivos aparecen felinos, antropomorfos, cabezas triangulares de saurios, loros, sapos felinizados, entre otros (Sempé y Baldini 2005).

Sobre la base de estas caracterizaciones de la cerámica tipo Aguada en los valles, en ANS los fragmentos asignados a esta tipología muestran una mayor similitud con la cerámica del valle de Abaucán, como ya se había sugerido previamente (Olivera, 1992). Las semejanzas se observan especialmente en aspectos decorativos de las vasijas, en los que la técnica principal de decoración es la aplicación de pigmentos sobre la superficie, especialmente pintura negra sobre engobe coloreado y fondo natural, teniendo en cuenta la caracterización de Feely (2013) (Figura 6).

Tabla 6. Porcentajes de técnicas decorativas en Hualfín, Abaucán y ANS.

\begin{tabular}{|c|c|c|c|}
\hline & Hualfín & Abaucán & ANS \\
\hline Técnica decorativa & & & \\
\hline Incisión & $82 \%$ & $25 \%$ & $15 \%$ \\
\hline Agregado de materia & & & $4 \%$ \\
\hline Pintura & $18 \%$ & $75 \%$ & $25 \%$ \\
\hline \multicolumn{1}{|l|}{} \\
\hline Neg sobre fondo nat. & & $57 \%$ & $19 \%$ \\
\hline Ro sobre fondo nat. & & $4,40 \%$ & $4 \%$ \\
\hline Neg y ro sobre fondo nat. & & - & $33 \%$ \\
\hline Neg sobre engobe coloreado &
\end{tabular}

(Referencias: neg, negro; ro, rojo; nat, natural. 
Siguiendo esta faceta de la cerámica, las similitudes se extienden al aspecto iconográfico, debido a que los motivos geométricos (escalonados compuestos, rombos) aparecen sobre todo en los momentos iniciales de Aguada en Abaucán (Sempé, 1976), de la misma forma que en CChM las figuras geométricas, especialmente figuras lineales pintadas, aparecen en mayor proporción que las imágenes figurativas. Hay que tener en cuenta, sin embargo, que en algunos fragmentos, debido a su estado de conservación y a su tamaño, no se pudo identificar más detalladamente de qué tipo de figuras geométricas se trataba (escalonados, rombos, lineales, etc.). Por ello, consideramos necesario ampliar la muestra disponible, tanto de CChM como de otros sitios de ANS, para poder identificar con mayor certeza cuáles son las imágenes geométricas más habituales en la cerámica Aguada de la microrregión.
En lo que se refiere a las imágenes figurativas, estas siempre aparecen asociadas a la técnica de incisión compuesta. Entre estas imágenes, se reconocieron figuras antropomorfas, una figura de batracio felinizado y una figura ofídica. Una de las imágenes antropomorfas fue identificada como Aguada, con base en el tocado compuesto en parte por un ofidio de cabeza triangular y cuerpo recto atravesando su cabeza (Figura 7). Este motivo se asocia a la figura del sacrificador, cuando aparece representando una flecha que es sostenida por dicho personaje (Baldini y Sempé, 2005). Es notable que los fragmentos con pastas más porosas y texturas medianas o gruesas se vinculan siempre a motivos lineales, pintados en negro o rojo sobre fondo natural o engobe coloreado, mientras que los fragmentos con pastas compactas se asocian tanto con motivos geométricos como con figurativos (Casanova Menéndez, 2017).

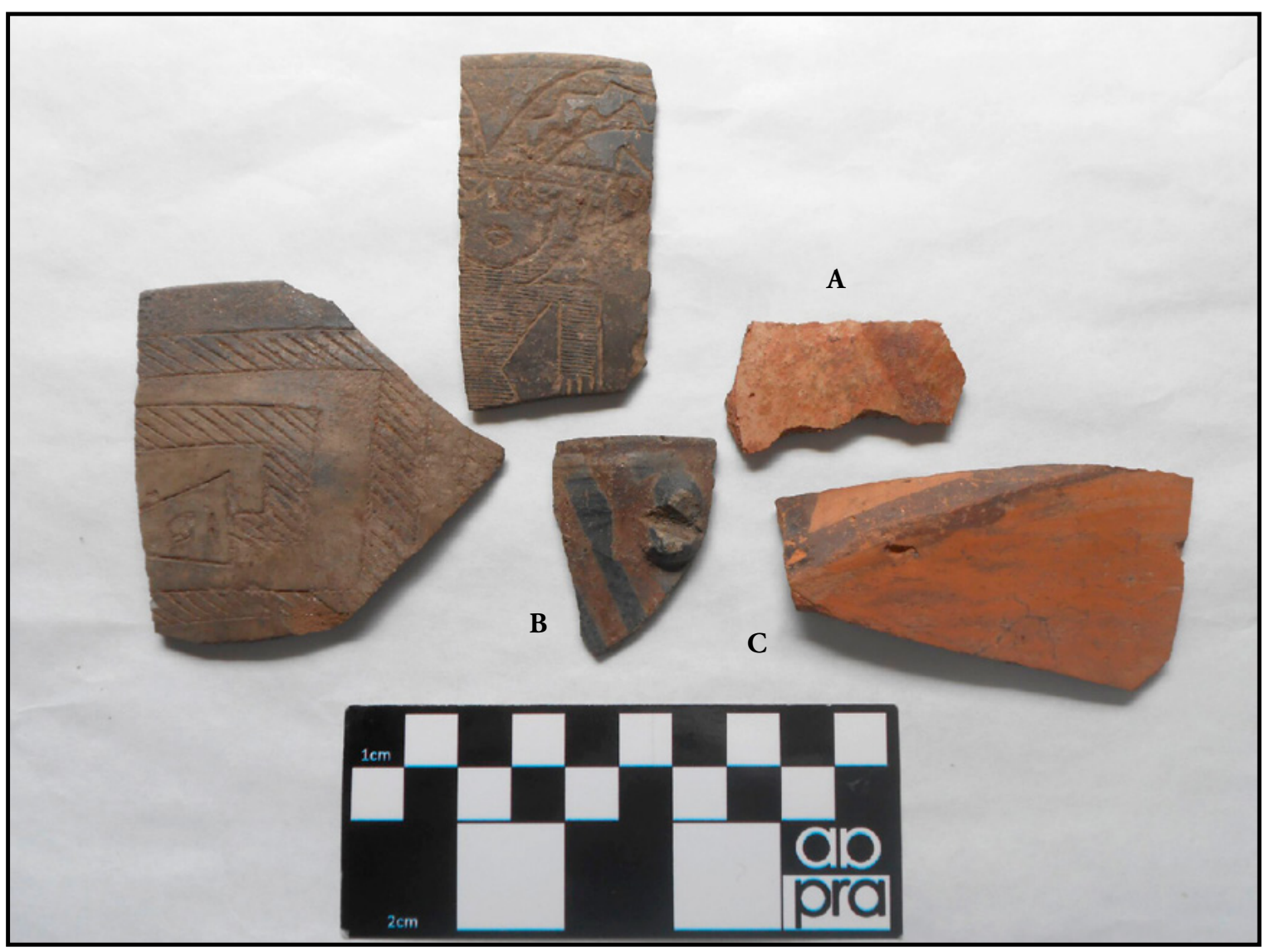

Figura 6. Cerámica Aguada hallada en CChM. A. Pintado en rojo sobre fondo natural. B. Pintado en negro sobre engobe coloreado. C. Pintado en negro sobre fondo natural. 


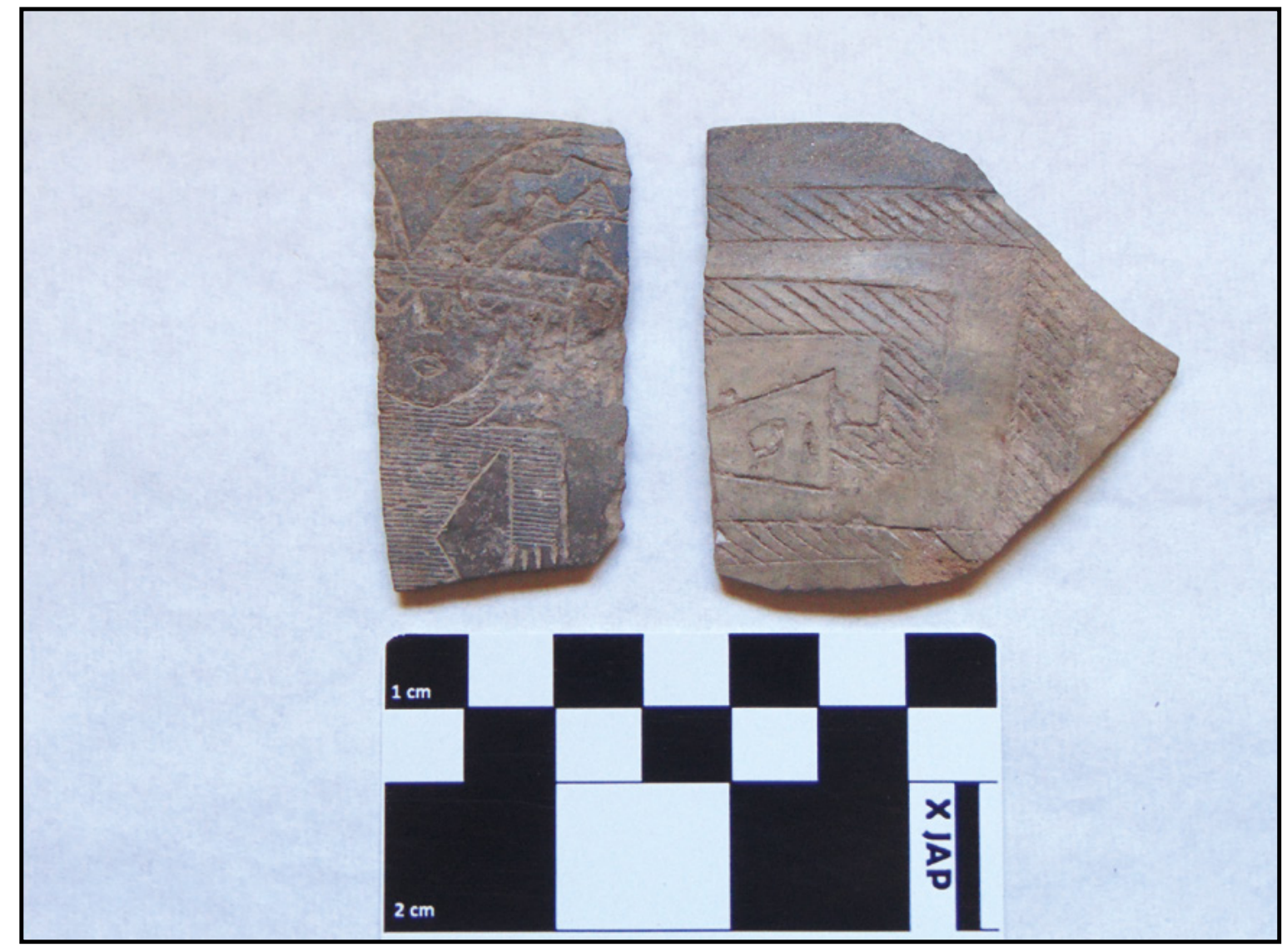

Figura 7. Cerámica Aguada incisa de CChM.

Considerando el aspecto tecnológico de los fragmentos, las similitudes entre ambas regiones no son tan marcadas, ya que se dan en algunos rasgos del proceso de manufactura como el acabado de superficie, primordialmente pulido, y las pastas preponderantemente compactas/muy compactas. Sin embargo, el proceso de cocción difiere de una región a otra: en Abaucán las atmósferas oxidantes son mayoritarias (Feely, 2013), mientras que para CChM la atmósfera de cocción reductora es la más común, aunque las pastas oxidantes e incompletas aparecen también representadas.

Por último, queremos resaltar el hallazgo en el sitio de una figurina antropomorfa modelada en arcilla e identificada como Aguada, encontrada en el Montículo 4. Este tipo de figuras fueron ubicadas en diferentes valles del NOA, como Chaschuil y Abaucán, entre otros (Raviña y Callegari, 1998), y se trata siempre de representaciones humanas, femeninas o masculinas, con alturas promedio de entre 7 y 13 $\mathrm{cm}$. La hallada en CChM tiene 6,0 $\mathrm{cm}$ de ancho y $5,2 \mathrm{~cm}$ de alto, sin contar la parte faltante del cuerpo por encima de los hombros (Figura 8) y presenta mayor grado de similitud con el grupo caracterizado por Raviña y Callegari (1998) como especímenes confeccionados sobre una gruesa plancha de arcilla modelada para obtener un cuerpo aplanado casi rectangular. Este tipo de figurinas procede mayormente de La Rioja o del sur de la provincia de Catamarca. Una característica específica de la figurina aquí analizada, y que la diferencia de la mayoría de este tipo de piezas, es el tipo de cocción incompleta, con el margen externo oxidado y el margen interno reducido. 


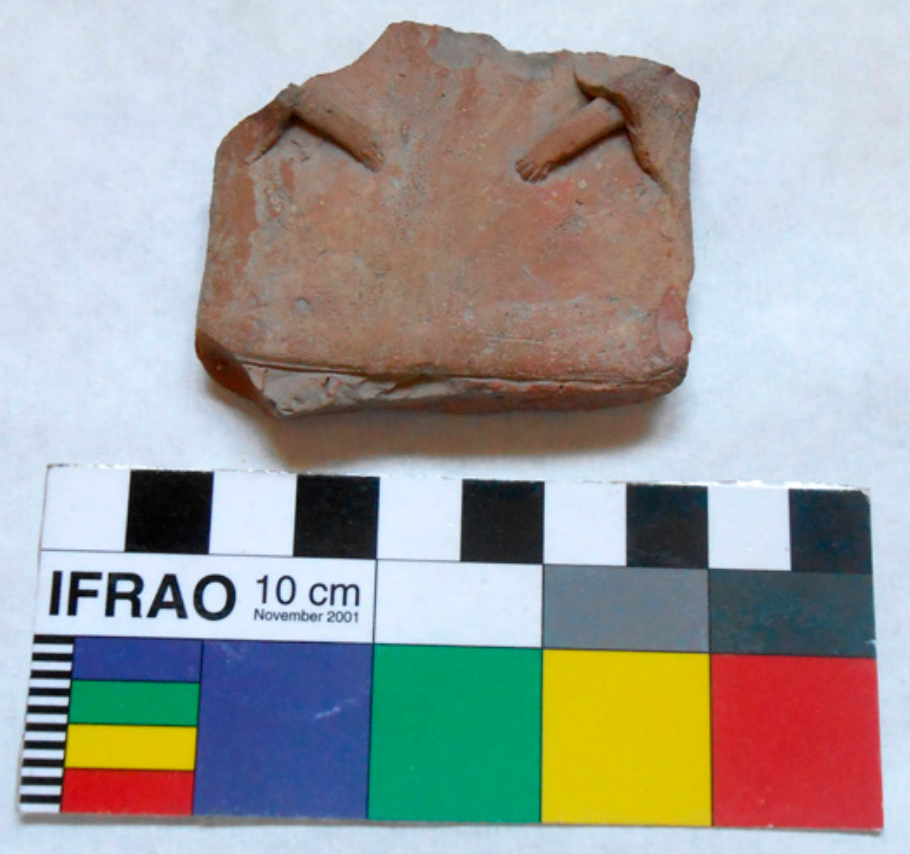

Figura 8. Figurina antropomorfa Aguada.

\section{Conclusiones}

El fenómeno Aguada en ANS se revela en el componente superior del sitio CChM, que corresponde al Formativo Medio y Tardío en la microrregión. Como en cada zona en que este proceso se desarrolló (Acevedo et al., 2015), en ANS también se manifestó con características propias de acuerdo a sus procesos históricos particulares, resaltando la identidad local de la comunidad, materializada en el estilo cerámico Aguada.

Nuestro trabajo considera 27 (veintisiete) fragmentos provenientes de un único sitio, que representan alrededor del $1,50 \%$ de la totalidad de los fragmentos con tratamientos decorativos, mientras Feely (2013) analiza el material de 13 (trece) sitios y solo identifica 135 (ciento treinta y cinco) fragmentos. Por lo tanto, una primera reflexión permite concluir que la presencia de la cerámica Aguada en estas regiones no es demasiado abundante, aunque no por ello deja de ser significativa.

La siguiente observación que surge del análisis es que, más allá de ciertos aspectos tecnológicos -textura de pasta, tamaño de las inclusiones y acabado de superficie- y decorativos que permiten adscribir los fragmentos analizados a tipos Aguada, existe alta variabilidad dentro de la muestra considerada.

El carácter local de Aguada en CChM se manifiesta en el aspecto tecnológico de la cerámica, particularmente en las atmósferas de cocción de los fragmentos analizados. Así, se observa una falta de homogeneidad en el tipo de cocción, dado que las atmósferas reductora, oxidante y mixta están representadas en proporciones similares, sin una clara predominancia de unas sobre otras. Este aspecto de la cerámica Aguada muestra una coherencia y con- 
tinuidad con el resto de la cerámica del sitio, tanto la decorada asignada a otras tipologías (Saujil y Ciénaga) como a los fragmentos de vasijas no decoradas (Vidal, 2001), desde las ocupaciones más tempranas hasta el evento de abandono definitivo del sitio. La falta de un control estricto sobre esta etapa de la cadena operativa por parte de los alfareros locales es especialmente visible en la figurina antropomorfa, ya que presenta un tipo de cocción mixto, cuando la mayor parte de este tipo de piezas halladas en otras regiones se caracterizan por ser totalmente oxidantes (Ravińa y Callegari, 1998). Esta particularidad que se presenta en toda la cerámica de CChM, especialmente en el Montículo 1, puede atribuirse, aunque no necesariamente, a una menor experiencia de los alfareros locales en el control del horno durante la cocción.

Tampoco puede descartarse una intencionalidad particular por parte de los artesanos en la búsqueda del producto final. Así, podemos considerar que esta característica responde a un proceso técnico fuertemente enraizado en las tradiciones tecnológicas de la comunidad alfarera local, existente desde el Formativo Temprano, y que se observa en otros aspectos del proceso de producción alfarero como la selección de antiplásticos de carácter local y, quizás, en la proporción de tipos de atmósfera. Respecto de esto último, podemos destacar que la relación de atmósfera reductora/incompleta vs. oxidante es de $70 \%$ vs. $30 \%$ en nuestro caso, frente a $25 \%$ vs. $75 \%$ en el detallado análisis de Feely (2013). Una causa posible de esta supremacía de la cerámica de pasta reductora en ANS está asociada a un mayor control de la entrada de oxígeno al horno, orientado a un ahorro del combustible debido a que la leña en la puna es un recurso escaso.

Sin embargo, puede sostenerse como hipótesis que no todas las vasijas Aguada fueron manufacturadas localmente, sino que algunas ingresaron terminadas probablemente desde el valle de Abaucán. Esta idea puede basarse en: a) el bajo porcentaje de fragmentos tipo Aguada sobre el total de fragmentos decorados en los niveles del sitio correspondientes al Formativo Tardío; b) la alta variabilidad en los aspectos correspondientes a los procesos de cocción reflejados en la secuencia cromática; y c) una alta variabilidad en las técnicas decorativas. Recorde- mos que en el valle de Abaucán se han desarrollado estudios petrográficos, químicos y tecnológicos sobre cerámica formativa local que demostraron que vasijas originarias de este valle tuvieron una amplia dispersión geográfica a través de la puna de Chaschuil, un área de nexo entre diversas regiones, entre las que se incluye ANS. De esta forma, se postula que Abaucán y ANS habrían participado de una red de circulación de personas, información y bienes (Ratto, Feely y Plá, 2013). Esta hipótesis también podría sustentarse en la alta circulación de bienes asociados a Aguada por regiones del área centro-sur andina ubicadas a ambos lados de la cordillera y que ha sido considerada por numerosos investigadores (p.e., Tarragó, 1976; Berenguer, 1984; Llagostera 1995; Acevedo et al., 2015, entre muchos otros). Si bien no existe acuerdo sobre la significación de estas evidencias asociadas al estilo Aguada en diferentes regiones, parecen indudables dos elementos: 1) su alto valor simbólico y de prestigio; y 2) que los objetos con iconografía Aguada circularon intensamente durante el primer milenio por la geografía de los Andes centro-sur.

Por otra parte, como observamos anteriormente, los atributos vinculados a la decoración de los fragmentos analizados muestran una gran similitud con la cerámica Aguada de diferentes sitios del valle de Abaucán. Estas características de la cerámica entran dentro de los procesos técnico-gestuales, aquellos más proclives a ser compartidos por diversas comunidades alfareras con diferentes niveles identitarios. Por lo tanto, mientras hay atributos tecnológicos que muestran una continuidad con los modos de producir cerámica localmente, los acabados de superficie, las técnicas decorativas y la iconografía de la cerámica Aguada antofagasteńa muestran una proximidad con los modos de hacer del valle de Abaucán. También el tipo de pasta, predominantemente fina y compacta, muestra similitudes con la cerámica Aguada de este valle, pero hay que tener en cuenta que esta característica excede a Abaucán y ANS, ya que la cerámica Aguada es generalmente de pasta fina y muy compacta, independientemente de su zona de procedencia.

Por último queremos remarcar que, a partir de la decoración y características tecnológicas, pudimos distinguir entre dos grupos de piezas. Por un lado, 
unas pocas piezas provenientes del Montículo 4 de muy buena factura técnica, pastas muy compactas y totalmente reducidas, superficies pintadas en gris y totalmente pulidas, decoradas mediante incisión en representaciones figurativas (específicamente una figura humana y otra ofídica). Por otro lado, un alto porcentaje de fragmentos, recuperados en su mayoría en el Montículo 1, caracterizados por pastas porosas, cocción oxidante o mixta, superficies pintadas $y$ pulidas, pero en ocasiones no de forma completa. Estas piezas siempre son decoradas mediante pintura y con representaciones lineales o geométricas.

Planteamos que la cerámica con las imágenes figurativas proveniente de CChM, estaría ante todo relacionada con la fase Tardía del Período Medio de Abaucán y al inicio de la fase Aguada en Hualfín, considerando que también coincide tecnológicamente con las piezas provenientes de este valle. Frente a esta situación, pueden sugerirse diversas explicaciones: 1) en CChM la cerámica del Formativo Medio-Tardío es producto de la influencia de las poblaciones de Abaucán; 2) se trata de cerámica que está presente desde una época más temprana en CChM y producto de contactos establecidos con Hualfín; 3) una combinación de ambas que implicara unas tempranas influencias desde Hualfín, luego reemplazadas por una mayor relación con Abaucán. Por el momento nos inclinamos por la hipótesis de que las principales influencias y/o relaciones se establecieron con el valle de Abaucán.

Sin poder descartar influencias del Aguada del Hualfín en momentos tempranos del proceso, la hipótesis precedente se apoya en: 1) los contextos del Formativo Medio y Tardío en ANS asocian numerosos fragmentos Aguada a tipos Ciénaga y Saujil de Abaucán (en particular los diseños decorativos con técnica de pulido diferencial); 2) las proporciones en la técnica decorativa de la cerámica de tipo Aguada de ANS tienen mayores similitudes con la de la región de Abaucán (ver Tabla 6); 3) en Laguna Blanca, que estaría idealmente en la trayectoria hacia ANS, es casi inexistente la presencia de fragmentos Aguada en los sitios Formativos que tradicionalmente se asocian a relaciones con el valle de Hualfín. Sin embargo, solo futuros estudios composicionales permitirán profundizar en las características tecnológicas anteriormente mencionadas, considerando que la composición de las pastas y su tratamiento es otro de los atributos que permite identificar tradiciones alfareras y es parte de los conocimientos y elecciones tecnológicos.

En relación a esto último, es importante mencionar los resultados obtenidos por López Campeny (2012), cuyo objetivo principal estuvo orientado a identificar la procedencia del conjunto cerámico que tradicionalmente fue vinculado a "estilos valliserranos" (Ciénaga, Saujil y Aguada) por investigadores precedentes (Olivera, 1992; Olivera y Podestá, 1993; Haber, 2001, 2006, 2007; entre otros). Para ello realiza una serie de análisis petrográficos y de activación neutrónica a un conjunto cerámico procedente de sitios ubicados en la margen sur del río Las Pitas, en los Sectores Intermedios de Antofagasta de la Sierra, cuyos fechados permiten correlacionar estos asentamientos con la ocupación de CChM. Los resultados obtenidos le permiten a la autora discriminar, en parte, aquellos fragmentos cerámicos de estilos valliserranos con aquellos de aparente tradición local, los primeros de ellos no homogéneos entre sí en cuanto a sus perfiles químicos multielementales y su composición petrográfica. En síntesis, fragmentos afines en sus características decorativas muestran composiciones que en algunos casos se relacionan con las materias primas locales y en otros son más afines a la geología propia de los valles mesotermales. Incluso, algunos fragmentos cuya iconografía es indiscutiblemente vallista muestran estar confeccionados con materias primas locales, lo cual refuerza nuestra hipótesis de la reticencia a modificar los procesos técnicos de la manufactura cerámica, entre los cuales se encuentra el procesamiento y elección de las materias primas.

Sin embargo, se debe tener prudencia con los resultados mencionados, ya que son diversas las dificultades al utilizar los datos petrográficos o de activación neutrónica para identificar procedencia, por lo cual es necesario el planteamiento de investigaciones más amplias que permitan profundizar en las interacciones de las sociedades del pasado. Es indiscutible, como ya se ha planteado en trabajos anteriores (Olivera, 1992; Olivera y Podestá, 1993), la influencia vallista en estas sociedades alfareras, pero todavía queda por dilucidar más adecuadamente cuales fueron los mecanismos involucrados en estas relacio- 
nes. Creemos que el estudio tanto de los procesos técnicos como de los decorativos de las tradiciones alfareras locales permitirá continuar aportando a la comprensión de las dinámicas sociales durante el Formativo en ANS.

Las conclusiones precedentes deberán ser contrastadas en el futuro mediante la ampliación cuantitativa del material analizado y de análisis petrográficos en proceso, tanto de cerámica proveniente de CChM como de otros sitios ubicados en diferentes sectores ecológicos de ANS. Sin embargo, esperamos que el presente trabajo contribuya a conocer con más detalle el desarrollo del Período Formativo Medio y Tardío en la microrregión, especialmente en lo referente a las vías de acceso seguidas por los grupos humanos de los valles ubicados al este y sur de ANS que tuvieron influencia sobre las poblaciones locales, incluso contribuyendo a aumentar la demografía local durante este período (Olivera, 1997).

\section{Agradecimientos}

A la comunidad de Antofagasta de la Sierra. A los integrantes del Proyecto Arqueológico Antofagasta de la Sierra por su colaboración en las tareas de campo. A las doctoras Norma Ratto y Mara Basile por sus útiles aportes y comentarios. A los evaluadores por sus oportunas sugerencias que ayudaron a mejorar el trabajo. Finalmente, este trabajo fue realizado en el marco de subsidios otorgados por la Universidad de Buenos Aires (Programa UBACyT-PIUBACC), la Agencia Nacional de Promoción Científica y Tecnológica (FONDCYT-ANPCYT) y el Consejo Nacional de Investigaciones Científicas y Técnicas (CONICET).

\section{Referencias citadas}

Acevedo, V. J., López, M. A., Callegari, A., Freire, E., Halac, E. B., Polla, G. y Reinoso, M. (2015). Estudio tecnológico de diseños "estilo Aguada" realizados sobre fragmentos cerámicos. En Pifferetti, A. y Dosztal, I. (Eds.). Arqueometria argentina. Metodologias cientificas aplicadas al estudio de los bienes culturales. Datación, caracterización, prospección y conservación, 109-125. Buenos Aires: Aspha Ediciones.
Albeck, M. E. y Scattolin, M. C. (1984). Análisis preliminar de los asentamientos prehispánicos de Laguna Blanca (Catamarca) mediante el uso de la fotografía aérea. Revista del museo de La Plata, 8, 279-302.

Aldunate, C., Berenguer, J., Castro, V., Cornejo, L., Martínez, J. y Sinclaire, C. (1986). Sobre la cronología del Loa superior. Chungara, 16-17, 333-346.

Babot, M., Aschero, C., Hocsman, S., Haros, M., González Baroni, L. y Urquiza, S. (2006). Ocupaciones agropastoriles en los sectores intermedios de Antofagasta de la Sierra (Catamarca): un análisis desde Punta de la Peńa 9.I. Comechingonia, 9, 57-75.

Baldini, M. y Sempé, M. C. (2005). El Estilo Aguada: Su Iconografía y la Imagen del Sacrificador. En Sempé, C., Salceda, S. y Mafia, M. (Eds.). Azampay. Presente y pasado de un pueblito catamarqueño. Antología de estudios antropológicos, 333-346. La Plata: Al Margen.

Balesta, B., Zagorodny, N. y Valencia, C. (2009). Evidencias de estandarización en la manufactura de cuencos de La Aguada Orilla Norte (Argentina). Estudios Atacameños. Arqueología y Antropología Surandinas, 37, 79-89.

Berenguer, J. (1984). Hallazgos La Aguada en San Pedro de Atacama, Norte de Chile. Gaceta Arqueológica Andina, 12, 12-14.

Callegari, A., Spengler, G. y Rodríguez, M. G. (2015). La complejidad social en Aguada. El caso del valle de Antiaco, departamento de Famatina, Norte de la provincia de La Rioja (Argentina). Arqueología, 21. Dossier, 111-137.

Casanova Menéndez, M. T. (2017). Arte y tecnología en la aldea Casa Chávez Montículos: definiendo un estilo cerámico local en Antofagasta de la Sierra (Catamarca, Argentina). Tesis de Licenciatura inédita, Facultad de Filosofía y Letras, Universidad de Buenos Aires, Buenos Aires, Argentina.

Chilton, E. (1999). One size fits all. Typology and alternatives for ceramic research. En Chilton, E. (Ed.). Material meanings: critical approaches to interpreting material culture, 44-60. Utah, UT, University of Utah Press.

Cohen, L. (2005). Entre guano y arena... Ocupaciones recurrentes: un caso de estudio en el sitio Punta de la Peña 9-III. Antofagasta de la Sierra, Catamarca. Tesis de Licenciatura. 
Universidad Nacional de Tucumán, Tucumán, Argentina.

Escola, P. S., Campeny, S. L., Martel, A., Romano, A. S., Hocsman, S. y Somonte, C. (2013). Reconociendo un espacio. Prospecciones en la Quebrada de Miriguaca (Antofagasta de la Sierra, Catamarca). Andes, 24, 397-423.

Feely, A. (2013). Los modos de hacer vasijas: elecciones técnicas y estilos tecnológicos del oeste tinogasteño (Catamarca). En Ratto, N. (Comp.). Delineando prácticas de la gente del pasado. Los procesos socio-históricos del oeste tinogasteño (Catamarca) (pp. 69-130). Buenos Aires: Publicaciones de la Sociedad Argentina de Antropología.

García Roselló, J. y Trías, M. (2006). Análisis de las evidencias macroscópicas de cocción en la cerámica prehistórica: una propuesta para su estudio. Mayurqa, 31, 83-112.

González, A. R. y Cowgill, G. L. (1975). Cronología arqueológica del Valle de Hualfin, Pcia. de Catamarca, Argentina. Obtenida mediante el uso de computadoras. Actas y Trabajos del Primer Congreso Nacional de Arqueologia Argentina, 383-404.

Gordillo, I. (1999). Problemas cronológicos del Período Medio en el Noroeste Argentino. En Diez Marín, C. (Ed.). Actas del XII Congreso Nacional de Arqueología Argentina II (pp. 362-371). La Plata, Universidad Nacional de La Plata, Argentina.

Gosselain, O. P. (2000). Materializing identities: an African perspective. Journal of Archaeological Method and Theory, 7(3), 187-217.

Haber, A. (2001). El oasis en la articulación del espacio circumpuneño. Actas del XIII Congreso Nacional de Arqueología. Tomo 1, 251-267, Universidad Nacional de Córdoba, Córdoba, Argentina.

Haber, A. (2006). Una arqueología de los oasis puneños. Domesticidad, interacción e identidad en Antofalla. Primer y segundo milenios DC. Córdoba: Universitas Libros. En coedición con la Universidad del Cauca, Colombia.

Haber, A. (2007). Comentarios marginales. En Williams, V., Ventura, B., Callegari, A., y Yacobaccio, H. (Eds.). Sociedades precolombinas surandinas: Temporalidad, interacción y dinámica cultural del NOA en el ámbito de los Andes Centro-Sur (pp. 59- 72). Michigan, MI: Kan Sasana Printer, University of Michigan.
Kligmann, D. M., Ratto, N. y Maidana, N. (2013). Microarqueología y procesos de formación del registro: análisis mineralógicos y diatomológicos del sitio El Zorro (Puna transicional, departamento de Tinogasta, Catamarca). En Ramos, M., Lanza, M., Helfer, V., Pernicone, V., Bognanni, F., Landa, C., Aldazabal, V. y Fernández, M. (Eds.). Arqueología Argentina: estudios pluridisciplinarios, 113-135. Buenos Aires: Aspha.

Lemmonier, P. (1993). Introduction. En Lemonnier, P. (Ed.). Technological choices: transformation in material cultures since the Neolithic, 1-35. London: Routledge.

Llagostera, A. M. (1995). El componente cultural Aguada en San Pedro de Atacama. Boletín del Museo Chileno de Arte Precolombino, 6, 9-34.

Llagostera, A. M., Barón, A. M. y Bravo, L. (1984). Investigaciones arqueológicas en Tulor 1. Estudios Atacameños, 7, 5-15.

López Campeny, S. L. (2001). Actividades domésticas y uso del espacio intrasitio. Sitio Punta de la Peña 9 (Antofagasta de la Sierra, Catamarca). Tesis de Licenciatura en Arqueología. Universidad Nacional de Tucumán, Tucumán, Argentina.

López Campeny, S. L. (2012). ¿De valles o de Puna? Discutiendo interacción a partir de la caracterización composicional de conjuntos cerámico. El caso de Antofagasta de la Sierra, Puna Sur Argentina. Estudios Atacameños. Arqueología y Antropología Surandinas, 43, 139-166.

Olivera, D. E. (1988). La ocupación productiva: apuntes para el análisis de sistemas adaptativos de tipo formativo en el Noroeste Argentino: En Precirculados del IX Congreso de Arqueología Argentina (pp. 83-101). Buenos Aires: UBA.

Olivera, D. E. (1992). Tecnología y estrategias de adaptación en el Formativo (agro-alfarero temprano) de la Puna Meridional Argentina. Un caso de estudio: Antofagasta de la Sierra (Pcia. de Catamarca, R.A.). Tesis Doctoral en Cs. Naturales, inédita, Facultad de Ciencias Naturales, Universidad Nacional de La Plata, La Plata, Argentina.

Olivera, D. E. (1997). Los primeros pastores de la puna sur argentina: una aproximación a través de su cerámica. Revista de Arqueología Americana, 13, 69-112. 
Olivera, D. E. (1998). Cazadores y pastores tempranos de la Puna Argentina. En Ahlgren, S., Muñoz, A., Sjodin, S. y Stenborg, P. (Eds.). Past and present in Andean prehistory and early history (pp. 153-180). Goteborg, Suecia: Etnologiska Studier.

Olivera, D. E. (2006). Recursos bióticos y subsistencia en sociedades agropastoriles de la Puna Meridional Argentina. Comechingonia, 9, 19-55.

Olivera, D. E. y Podestá, M. (1993). Los recursos del arte: arte rupestre y sistemas de asentamiento-subsistencia formativos en la Puna Meridional Argentina. Arqueología, 3, 93-141.

Olivera, D. E., Elías, A., Pérez, M. y Salminci, P. (2015). Corral Grande 1 y Arroyo Seco: nuevos aportes al Formativo de Antofagasta de la Sierra (Provincia de Catamarca, Puna Meridional Argentina). Comechingonia. Revista de Arqueología, 19, 37-66.

Ratto, N. (2013). A modo de introducción: la articulación de estudios arqueológicos, paleoambientales e históricos en el oeste tinogasteño (Catamarca). En Ratto, N., (Comp.). Delineando prácticas de la gente del pasado. Los procesos socio-históricos del oeste tinogasteño (Catamarca) (pp. 17-44). Buenos Aires: Publicaciones de la Sociedad Argentina de Antropología.

Ratto, N., Feely, A. y Plá, R. (2013). Vasijas y barros: una aproximación a la producción, distribución y consumo en el oeste tinogasteńo, siglos I al XIII. En Ratto, N. (Comp.). Delineando prácticas de la gente del pasado. Los procesos socio-históricos del oeste tinogasteño (Catamarca), 135-161. Buenos Aires: Publicaciones de la Sociedad Argentina de Antropología.

Raviña, M. G. y Callegari, A. (1998). Las figurinas de la cultura de la Aguada. Corpus Antiquitatum Americanensium. Argentina, II, 1-61. Buenos Aires: Academia Nacional de la Historia.

Rice, P. M. (1987). Pottery analysis: a sourcebook. Chicago, IL: University of Chicago Press.

Rye, O. S. (1981). Pottery Technology. Principles and Reconstruction. Manuals on Archaeology, 4. Washington, DC: Taraxacum.
Sempé, M. C. (1976). Contribución a la arqueología del Valle de Abaucán. Tesis doctoral en Cs. Naturales, Facultad de Ciencias Naturales y Museo, Universidad de La Plata, La Plata, Argentina.

Sempé, M. C. (1998). Contacto cultural en el sitio Aguada Orilla Norte. En FADA-UBA (Ed.). Homenaje a Alberto Rex González, 50 años de aportes al desarrollo y consolidación de la antropología argentina (pp. 255-283). Facultad de Filosofía y Letras, UBA, Buenos Aires, Argentina.

Sempé, M. C. y Baldini, M. I. (2005). La cerámica Aguada gris grabada y su contexto funerario. En La cultura de la Aguada y sus expresiones regionales (pp. 129-140). EUDELAR - Museo de Ciencias Naturales - Universidad Nacional de La Rioja, La Rioja, Argentina.

Tarragó, M. (1976). Alfarería típica de San Pedro de Atacama (Norte de Chile). Estudios Atacameños, 4, 37-67.

Tarragó, M. (1989). Contribución al conocimiento arqueológico de las poblaciones de los oasis de San Pedro de Atacama en relación con los otros pueblos puneños, en especial, el sector septentrional del Valle Calchaqui. Tesis de doctorado en Antropología, Facultad de Humanidades y Artes, Universidad Nacional de Rosario, Rosario, Argentina.

Trías, M. y García Roselló, J. (2012). Tradición técnica y contactos: un marco de reflexión centrado en la producción cerámica. Revista del Museu de Gavá, 5, 393-401.

Vidal, A. S. (2001). Análisis de la cerámica utilitaria en un sitio agroalfarero temprano en la Puna de Catamarca. Tesis de Licenciatura en Cs. Antropológicas, Facultad de Filosofía y Letras, Universidad de Buenos Aires, Buenos Aires, Argentina.

Zagorodny, N., Balesta, B., Ávalos, G., Valencia, C. y Gómez Ferreiro, M. J. (2005). Homogeneidad y permanencia en la manufactura de los pucos de La Aguada Orilla Norte. En La cultura de la Aguada y sus expresiones regionales (pp. 129-140). EUDELAR - Museo de Ciencias Naturales - Universidad Nacional de La Rioja, La Rioja, Argentina. 